\title{
National Health Policy of Nepal-Time to Revisit and Reform
}

\author{
Angel Magar ${ }^{1}$ \\ ${ }^{1}$ Nepal Health Research Council, Kathmandu, Nepal.
}

The Health Policy is one of the most important aspect of development of health of a country. It is particularly, important in a country like ours where resources and technology are more limited than in other countries. The National Health Policy (NH) of Nepal was adopted in 1991 to bring about improvement in the health conditions of the people of Nepal. The primary objective of the National Health Policy was to extend the primary health care system to the rural population so that they could benefit from modern medical facilities and trained health care providers with the objective of improving the health of the most vulnerable groups, women and children, the poor and the underprivileged and marginalized population of the country. ${ }^{1}$ With this vision, the main objectives were to upgrade the health standards of the majority of the rural population by extending basic primary health service up to the village level and, to provide opportunity to the rural people to enable them to obtain the benefits of modern medical facilities accessing them. It also focused on addressing disparities in the health status, assuring equitable health care with full community participation and gender sensitivity by focusing Government of Nepal and external donor partners (EDP) fund on area of necessity, also avoiding duplication of similar works and ensuring effective use of public private partnerships.

Hence, 1991 National Health Policy was broadly categorized in three groups; Preventive, Promotive and Curative Health Services. In the year 2004, health sector strategy agenda for reform was developed to implement fiveyear strategic plan. ${ }^{2}$ The Ministry of Health and Population (MoHP) began sector wide approach (SWAp), Nepal Health Sector Program (NHSP) 2005-2010 and NHSP-2 2010-2015 with universal health coverage in priority which will also initiate NHSP-3 development process. ${ }^{3}$

The population of Nepal has doubled since the adoption of NHP in 1991, we are have growing population, migration and rapid urbanization throughout the country. The interim constitution has also states health as the fundamental rights of all Nepalese citizens because of which new programs such as Free Health Care, Aama Surakshya Karyakram, Free Uterine Prolapse Programs has been initiated. As with the growth of population, literacy rate has also increased, consequently there are growing expectations from the citizens on equitable access to quality health care services. On the top of that there are many other challenges such as emergence of new diseases, increasing burden of non-communicable diseases (NCDs), shifting global priorities in health such as MDGs and beyond MDGs. All this issues has demanded for broader partnership in health such as partnership of the MoHP with professional associations like Nepal Medical Association, Nepal Nursing Associations and other health professional associations and societies, civil societies, private medical and health institutions etc. There is also need of multi sectorial response for in the various health issues such as nutrition, road traffic accidents and safety, environmental health and sanitation and many more.

The development of health policy is also a dynamic process, periodical revisit of the policy, its consultations, discussions with fruitful debates; updates and continuous works help achieve its goals. The Policy recognizes the challenges of consolidating the principles of the previous health policy in community involvement, improved health services provision, access and equity while addressing the different dimensions of reforms that are taking place in the Public Sector.

National health policies, strategies, and plans play an essential role in defining a country's vision, priorities, budgetary decisions and course of action for improving and maintaining the health of its people. Most countries have been using the development of national health policies, strategies, and plans for decades to give direction and coherence to their efforts to improve health. ${ }^{4}$ Unfortunately, most nation have taken "health policy" to mean "medical care policy." Medical care, however, is only one variable in a nation's health equation. Instead, it should include; the political, economic, social, and cultural determinants of health, the most important determinants of health in any country; the lifestyle determinants, which have been the most visible types of public interventions; and the socializing and empowering determinants too. The effective long term out come of any health policy depends to the large degree on the political will of the national authorities and the broad understanding of the actual determinants of health. ${ }^{5}$

Correspondence: Dr. Angel Magar, Nepal Health Research Council, Kathmandu, Nepal. Email: ang2el@gmail. com, Phone: 977-1-4254220. 
Nepal is a landlocked country with great physical diversity and difficult terrain. The population comprises many caste/ethnic groups, religions and languages. The planned development in health started in 1956. There have been ten medium term plan of five years duration, an interim three year plan for 2007-2010 and two long term health plan- first (1975-1990) providing framework for regionalization, basic health services, and with focus on rural health service and the second (1995-2015) to address to equitable health service with gender sensitivity and directed to the poor, vulnerable and marginalized with active involvement of community in line with National health policy 1991 . Health sector strategy was formulated in 2004 in the spirit of the Paris Agreement for aid effectiveness and SWAp was pursued through a Memorandum of Understanding (MOU). Accordingly, NHSP- IP 1 was formulated for 2004-09 and implemented. There has been active participation of community level outreach health workers and social groups at local level with wide use of low-cost technology.

During the last two decades, in particular, significant improvement has been noted in health outcomes and impact with steady improvement in the indicators, despite a decade of conflict situation in the country. Nepal is on track to meet the Millennium Development Goals on maternal and child health. Major policy initiatives like maternal incentives for free delivery, pro-poor scheme for medical services, free essential health care services have contributed to improvement in health status and in addressing inequity. Further, politically, the country is in the process of going to federal structure. This will not leave any area of the health system, from planning to service delivery and overall health governance unaffected. Acute preventable childhood diseases, complications of childbirth, nutritional disorders and endemic diseases continue to be prevalent. Non-communicable diseases are assuming relative importance with threat from life style and dietary patterns. The poor are no exempt. Indoor pollution from smoke due to burning of fuel from cooking and tobacco has also contributed to the burden of non-communicable diseases. Further, explosives including landmines have taken their toll on injuries and even deaths during insurgency and unexploded ordnances continue to pose the risk.

The Government is committed to health sector development as evidenced by increase in budget, there has been development of infrastructure from the central to the peripheral level with outreach facilities. The interim Constitution of Nepal 2063 declaring and enshrining the state's commitment and responsibility to people's health with a comprehensive vision of an inclusive society. Despite of which we have; continuing significant level of inequity in health outcomes, poor people have low access to health care services, poor management of health workforce and there is paucity of disaggregated data in relation to universal coverage on primary health care to address equity and needs and also there is lack of inter-sectoral coordination.

Now, the time has come to sustain the gains achieved so far and continue improvement and to keep the EDPs engaged in the process with good governance, transparency and understanding to sustain and increase their support. This is high time Nepal should revisit, revise and reform national health policy according to the present context envisioning future challenges.

\section{REFERENCES:}

1. Ministry of Health and Population. National Health Policy, 1991 [Online]. [Cited 2013 Jun 15]. Available from: URL:http://www.mohp.gov.np/english/publication/national_health_policy_1991.php

2. Ministry of Health and Population. Nepal Health Sector Programme - Plan (NHSP-IP) 2004-2009 [Online]. [Cited 2013 Jun 15]. Available from: URL:http://www.mohp.gov.np/english/publication/national_health_policy_1991. php

3. Ministry of Health and Population. Health Sector Strategies, Oct 2004 [Online]. [Cited 2013 Jun 09]. Available from: http://www.mohp.gov.np/english/publication/HSSR\%20Agenda.pdf

4. World Health Organization. National health policies, strategies and plans [Online]. [Cited 2013 Jun 09]. Available from: URL: http://www.who.int/nationalpolicies/en/

5. Navarro V. What is a national health policy? Int J Health Serv. 2007;37(1):1-14. 